\title{
Relationship between Family Functioning and Environmental Attitudes on the Environmental Behaviours of Students in a Federal University in Edo State, Nigeria
}

\author{
Norris Igbinosa Erhabor ${ }^{1 *}$, Cynthia Oviahon ${ }^{2}$ \\ ${ }^{1}$ Department of Health, Safety and Environmental Education University of Benin, Benin, NIGERIA \\ ${ }^{2}$ University of Benin, Benin, NIGERIA
}

*Corresponding Author: norris.erhabor@uniben.edu

Citation: Erhabor, N. I. and Oviahon, C. (2018). Relationship between Family Functioning and Environmental Attitudes on the Environmental Behaviours of Students in a Federal University in Edo State, Nigeria. European Journal of Sustainable Development Research, 2(3), 28. https://doi.org/10.20897/ ejosdr/ 87022

Published: July 9, 2018

\begin{abstract}
The aim of this study is to investigate the relationship between family functioning and environmental attitudes toward students' environmental behaviours. This study was done in view of guiding both stakeholders and parents including school administrators on proper tips for boosting student behaviours towards the environment in order to build a more friendly and sustainable environment in Edo State and Nigeria as a nation. A correlational study was embarked on. The population and sample of the study consisted of all full time (200Level to 400Level) environmental education students in University of Benin, Nigeria. Thus one hundred and two students constituted the sample for the study. Hence a census sampling technique was utilized in the study. Family functioning was seen to have a stronger influence on the environmental behaviour of the students than their environmental attitude. Meanwhile the combination of family functioning and environmental attitude was seen to have a significant influence on the environmental behaviours of the students.
\end{abstract}

Keywords: environmental education, family functioning, environmental attitude, environmental behaviour

\section{INTRODUCTION}

Often times an ideal family could be seen as family that have high family bonding. By bonding we are referring to a situation in which each members of same family relies on one another for all kinds of support. This could be that the family draws inspirations, love, strength and motivation from one another. This is supported by a study conducted on Germans, that greater environmental concern was related not only to greater openness, but also to greater agreeableness that is the ability to be compassionate and cooperative rather than suspicious and antagonistic towards others especially in the family (Gifford and Nilsson, 2014). But a situation whereby family bond and cohesion is broken, frustration, stress and anger set in and ultimately impacts every member and if unresolved; it could have a far reaching implication on the status of members involved especially the children/wards of such family. This could also result in the development of negative attitude and behaviour towards the environment.

Globally, from the America perspective, it has been observed that fifty (50) years till now family functioning, patterns or types which could range from divorce, separated, drug addict to parents remarriage types of family, have its effects on the academic achievement or performance of the child. This can as well be perceived to be similar to the environmental attitudes and behaviour of a child /student as the case may be. Consequently, other developed and developing nations of the world are not exempted from this menace. 
In Nigeria, the researchers have observed that a relationship between family types and performance in general of a child is paramount in measuring success in them. In furtherance of this, it has been proven that responsible behaviours of students could be a reflection of the type of home functioning that the child is being raised. Plonin and Daniels (2011) are of the opinion that the greatest social significance that has emerged from human behaviourgenetic research to date evolved from nurture and not more in nature (also Owie and Eke-Huber, 2003; Pyper et al., 2016). According to Gifford and Nilsson (2014), how people relate to other people, has also been examined in relation to environmental concern and behaviour. A Canadian study found that independent self-construal (differentiating oneself from others) predicted egoistic environmental concern and competitiveness in sharing resources, interdependent self-construal (focusing on relationships with others) predicted resource cooperation and meta-personal self-construal (feeling fundamentally interconnected with all living things) predicted biospheric environmental concern, ecological cooperation and self reports of pro-environmental conservation behavior (Arnocky et al., 2007).

It has been observed by the researchers that studies on the relationship between family functioning, environmental attitudes and environmental behavior among students in Nigeria are few or nonexistence. However, a study embarked upon by De levega (2004) to assess the environmental attitude, knowledge and awareness of environmental specialist, high school instructors, students and parents revealed that environmental specialist scored highest for all component. Also, a study conducted by Caldwell (2011) on assessing Canadians' knowledge, attitude and practice to global environmental change and health revealed that the participants were aware and concerned about local environment and had limited knowledge of the details of specific causes, impacts and risks of climate change and global warming and they had the willingness to act in environmentally friendly manner. Kaiser, Ranney, Hartig and Bowler (1999) revealed a positive correlation between environmental attitude and environmental behaviors in their study. Studies by Eilam and Trop (2010) revealed that their respondents' posses' positive attitude towards the environment but the strategies required for influencing attitudes are different from those required for influencing behavior.

Thus, it is perceived that if there are parental support as regards to good family bonding and functioning it will have a far reaching influence on students thereby rubbing off on their environmental attitudes and behaviour of the students; hence the study. Based on the background of the study and problem discussed, the following research questions were proposed.

1. What are the environmental behaviour of environmental education students?

2. Do family functioning and environmental attitudes predict the environmental behaviours of environmental education students?

\section{RESEARCH HYPOTHESIS}

From the research question stated above the following null hypothesis were generated to be tested at 0.05 level of significance.

1. Family functioning and environmental attitudes do not significantly predicts the environmental behaviours of environmental education students

\section{METHODOLOGY}

The correlational research design was adopted for the study. The population and sample of the study consisted of all full time (200Level to 400Level) environmental education students in University of Benin, Nigeria. Thus one hundred and two students constituted the sample for the study. This shows that a census sampling technique was adopted for the study. Hence, a questionnaire titled "influence of family functioning and environmental attitudes on the environmental behaviours of students" was used. It was divided into four sections (A, B, C and B). Section A was used to elicit responses biodata and section $B$ was used to measure family functioning. While section $\mathrm{C}$ and $\mathrm{D}$ elicited data on environmental attitude and environmental behaviours respectively. The questionnaire items were based on a four point likert scale of Strongly Agree (SA)- 4, Agree (A)-3, Disagree (D)-2, Strongly Disagree (SD)1 and the negatively worded questions were coded inversely. A test retest method was used to assess the reliability of the instrument through the administering of the instrument to twenty (20) students. And a correlation coefficient of 0.87 was derived. This was considered adequate for the study. The researchers administered the questionnaires personally with two trained research assistants. Thereafter face to face method was adopted to make sure that the respondents which the questionnaires were meant for effectively filled it. 
European Journal of Sustainable Development Research, 2(3), 28

Table 1. Environmental behaviours of the students

\begin{tabular}{lcccc}
\hline & Frequency & Percent & Valid Percent & Cumulative Percent \\
\hline proenvironmental & 75 & 73.5 & 73.5 & 73.5 \\
\hline anti environmental & 27 & 26.5 & 26.5 & 100.0 \\
\hline Total & 102 & 100.0 & 100.0
\end{tabular}

Table 2. Correlation matrix of criterion and predictor variables

\begin{tabular}{llccc}
\hline & & Behaviour & Attitude & \multicolumn{2}{c}{ Family } \\
\hline \multirow{2}{*}{ Pearson Correlation } & Behaviour & 1.000 & .202 & .282 \\
\cline { 2 - 5 } & Attitude & .202 & 1.000 & .589 \\
\cline { 2 - 5 } & Family & .282 & .589 & 1.000 \\
\hline \multirow{3}{*}{ Sig. (1-tailed) } & Behaviour & .021 & .021 & .002 \\
\hline & Attitude & .002 & .000 &. \\
\cline { 2 - 5 } $\mathrm{N}$ & Family & 102 & 102 & 102 \\
\hline & Behaviour & 102 & 102 & 102 \\
\cline { 2 - 5 } & Attitude & 102 & 102 & 102 \\
\cline { 2 - 5 } & Family & &
\end{tabular}

Table 3. Summary of hierarchical regression analysis for variables predicting environmental behaviours

\begin{tabular}{|c|c|c|c|c|c|c|c|}
\hline Variable & B & $\mathbf{F}$ & $\mathrm{t}$ & Std. error & $\mathbf{R}$ & $\mathbf{R}^{2}$ & $\mathbf{R}^{2} \triangle$ \\
\hline Stage 1 & & $8.647^{*}$ & & & 0.282 & 0.080 & 0.080 \\
\hline Family & 0.266 & & $2.941 *$ & 0.090 & & & \\
\hline Stage 2 & & $4.396^{*}$ & & & 0.286 & 0.082 & 0.002 \\
\hline Family & 0.235 & & $2.096^{*}$ & 0.112 & & & \\
\hline Attitude & 0.055 & & 0.461 & 0.119 & & & \\
\hline
\end{tabular}

$\mathrm{N}=102 * \mathrm{p}<0.05$

\section{RESULT}

\section{Research Question One: What are the Environmental Behaviours of Environmental Education Students?}

From Table 1, it can be deduced that $73.5 \%$ of the respondents opined that they exhibit pro-environmental behaviours (environmental friendly behaviours) while $26.5 \%$ stated that they exhibit anti environmental behaviours. This indicated that majority of the students possess pro-environmental behaviours.

Hypothesis one: Family functioning and environmental attitudes do not significantly predicts the environmental behaviours of environmental education students.

From Table 2, it shows the Pearson Correlation of the variables of the study. It can be deduced that the correlation between behaviour and attitude is a significant, weak positive relationship $(\mathrm{r}=0.202$, $\mathrm{p}<0.05)$, while the correlation between behaviour and family functioning is also a significant, weak positive relationship $(r=0.282$, $\mathrm{p}<0.05)$. However, a moderate positive relationship is observed between attitude and family functioning in the study $(\mathrm{r}=0.589, \mathrm{p}<0.05)$.

However, before using hierarchical multiple regression, the relevant assumptions of this statistical analysis were tested. A sample size of 102 is adequate given two independent variables. The assumption of singularity was also met. Thereafter an examination of correlation, it was deduced that no independent variables were highly correlated and the collinearity statistics (tolerance and VIF) were all within accepted limits. Hence assumption of multicollinearity was met.

Table 3 revealed from the hierarchical multiple regression that at stage one, family functioning contributed significantly to the regression model, $\mathrm{t}=2.941, \mathrm{p}<0.05$ and accounted for $8 \%$ of the variation in the environmental behaviours of the students. Meanwhile in stage two, both family functioning and environment attitude together contributed additional $8.2 \%$ of the variation in environmental behaviours and this change in $\mathrm{R}^{2}$ was significant, $\mathrm{F}(1,100)=4.396, \mathrm{p}<0.05$. However environmental attitude alone only contributed $0.2 \%$ to the model in explaining the variation in environmental behaviour and its contribution can be seen as not significant as $\mathrm{t}=0.461, \mathrm{p}>0.05$. Furthermore, family functioning had a significant positive regression weight $(B=0.235, \mathrm{p}<0.05)$ indicating that environmental education students with proper family functioning were expected to have pro-environmental behaviours (environmentally friendly behaviours). While environmental attitude had a non significant positive weight $(B=0.055, \mathrm{p}>0.05)$ which reveals that attitude did not significantly contribute to the multiple regression 
model. But together family functioning and environmental attitude significantly predicts the students environmental behaviours hence the null hypothesis is rejected.

\section{Discussion of Findings}

This study was designed to assess the influence of family functioning and environmental attitude on the environmental behaviours of environmental education students. The study revealed that majority of the students possess pro-environmental behaviours or are environmentally friendly. This is indicated from Table 1, as $73.5 \%$ of the respondents were deduced to have pro-environmental behaviours while $26.5 \%$ were seen possess antienvironmental behaviours. Some of the pro-environmental behaviours they reported to engage in are encourages the planting of trees in the surrounding, having internal discussion with friends and family on climate change, installing rain water tanks in my house in time of rain, looking after trees in my surrounding, give talk in the school about environmental issues and so on. This is inline with studies conducted by Digby (2010) which revealed proenvironmental behavior among Minnesota adults was mixed with some reporting they engaged in participating in some pro-environmental behaviors and not in others. While study of Gatersleben et al. (2002) showed that proenvironmental behavior is more strongly related to attitudinal variable.

Meanwhile, from the hierarchical multiple regression done in this study, the researcher observed a moderate positive relationship between family functioning and environmental attiude. Weak positive relationships were observed between family functioning and environmental behaviour and between environmental attitude and environmental behaviours respectively. These are inline with the study by report of Kaiser et al. (1999) which revealed a positive correlation between environmental attitude and environmental behaviors. Studies by Eilam and Trop (2010) revealed that the respondents' posses' positive attitude towards the environment but the strategies required for influencing attitudes are different from those required for influencing behavior.

To assess the influence of family functioning and environmental attitude on environmental behaviours of the students, it was observed from the multiple regression that a combination of family functioning and environmental attitude significantly predicted the environmental behaviours of the students. That is the two independent variables (family functioning and environmental attitude) explained $8.2 \%$ of the variation in the dependent variable (environmental behaviours). But only the family functioning variable explained $8.0 \%$ of the variance in the students environmental behaviours while environmental attitude alone explained $0.2 \%$ of the variance of the respondents environmental behaviours. Hence family functioning is seen as a stronger predictor of environmental behaviours among the respondents than environmental attitude. This is depicted in Table 3 as family functioning had Beta value of 0.235 which is significant at 0.05 alpha level while environmental attitude had Beta value of 0.055 which is not significant at 0.05 alpha level.

\section{CONCLUSION}

The study aimed to examine the influence of family functioning and environmental attitude on the environmental behaviours of environmental education students in the University of Benin. From the study it can be concluded that family functioning was seen to have a stronger influence on the environmental behaviour of the students in the study than their environmental attitude or concern showed to the environment. Meanwhile both family functioning and environmental attitude are seen to have a great influence on the environmental behaviours of the students. This shows that students from a good functioning family tend to behave in an environmentally friendly way that is they would show concern and act in ways to protect the environment.

\section{RECOMMENDATIONS}

Based on the findings of this study, the following recommendations were proposed by the researcher.

1. There should be increased awareness raising avenues on environmental education towards the general public.

2. Counseling specialist and environmental educators should collaborate to improve the environmental behaviour of students

3. Further studies should focus on larger and more diverse sample by gender, geography and ethnicity 


\section{REFERENCES}

Arnocky, S., Stroink, M. and DeCicco, T. (2007). Selfconstrual predicts environmental concern, cooperation, and conservation. Journal of Environmental Psychology, 27, 255-264. https://doi.org/10.1016/j.jenvp.2007.06.005

Caldwell, R. (2011). Knowledge, attitudes and practices of global environmental change and health: toward sustainable behaviour change. EdD Dissertation, Unpublished. Ontario: McMaster University-Hamilton.

de laVega, E. L. (2004). Awareness, Knowledge, and Attitude about Environmental Education: Responses from Environmental Specialists, High School Instructors, Students, and Parents. EdD Dissertation, Unpublished. Florida: University of Central Florida- Orlando

Digby, C. L. (2010). An Examination of the Impact of Non-formal and Informal Learning on Adult Environmental Knowledge, Attitudes, and Behaviors. EdD Dissertation, Unpublished. Minnesota. The University Of Minnesota.

Eilam, E. and Trop, T. (2010). Environmental attitudes and environmental behavior-which is the horse and which is the cart. Sustainability, 4, 2210-2246. https://doi.org/10.3390/su4092210

Gatersleben, B., Steg, L. and Vlek, C. (2002). Measurement and determinants of environmentally significant consumer behavior. Environment and Behavior, 34, 335-362. https:// doi.org/10.1177/0013916502034003004

Gifford, R. and Nilsson, A. (2014). Personal and social factors that influence pro-environmental concern and behaviour: A review. International Journal of Psychology, https:// doi.org/10.1002/ijop.12034

Kaiser, F. G., Ranney, M., Hartig, T. and Bowler, P. A. (1999). Ecological behavior, environmental attitude, and feelings of responsibility for the environment. European Psychologist, 4, 59-74. https://doi.org/10.1027//10169040.4.2.59

Melanie, P. (2014). Top 10: family issues you can overcome: www.lifehacker.com.

Owie, I and Eke-Huber, E. A. (2003). A brief introduction to: Mental Health Education. Edo State. Mindex Publishing pp. 55-56 ISBN 978-803541-8

Plonin, R. and Daniels, D. (2011).Why are children in the same family so different from one another? International Journal of Epidermiology, 40(3), 563-583. https://doi.org/10.1093/ije/dyq148

Pyper, E., Harrington, D. and Manson, H. (2016). The impact of different types of parental support behaviors on child physical activity, healthy eating and screen: a cross sectional study. BMC inclusive and trusted, 2(16), 568. 